\title{
An/Aesth/Ethics: the ethical potential of design
}

\author{
Peter Buwert, \\ School of Arts \& Creative Industries, Edinburgh Napier University, Edinburgh, Scotland
}

\begin{abstract}
Design is often thought of as an activity seeking to change existing situations into preferred ones (Simon, 1969). But how are designers to discern what the nature of this "preferred" change should be? What would it mean to truly design ethically? In the admirable but naïve quest to improve situations through design, it is possible to end up bypassing the ethical altogether. Design can aesthetically provide the appearance and sensation of ethicality without the inconvenience of actually having to be ethical. Ethical discomfort is anaesthetised through the process of aestheticizing ethics: an/aestheticization. Beginning with visual communication design, but maintaining a view to the applicability and importance of the argument for broader fields of design, this paper presents the case that there is hope for genuinely ethical design in an increasingly aestheticized world by drawing on German philosopher of aesthetics Wolfgang Welsch's suggestion that the root of ethics can be found to emerge from within the aesthetic itself. Design, which for so long has been a principal contributor to an/aestheticization, contains within itself - precisely due its aesthetic nature - the potential to return feeling to a society which finds itself constantly numbed to true ethical being.
\end{abstract}

Keywords: aesthetics, anaesthetics, blind-spot culture, graphic design, ethics

\section{AN/AESTH/ETHICS: THE ETHICAL WITHIN DESIGN.}

The question of the relationship between design, aesthetics and ethics is a fascinating one. Design often appears to inhabit a Janus-faced paradoxical position, torn between seeming to desperately want to "be good" yet ending up a lot (if not most) of the time having negligible positive ethical impact, perhaps even making things worse in the long term. In the face of massive environmental, economic, political and social challenges, many designers remain optimistic as to the power of their profession to change the world for the better. Perhaps emblematic of this idealism is the surge of interest and activity in recent years in the sphere of design activism. Alastair Fuad-Luke defines the design activist as "a person who uses the power of design for the greater good for humankind and nature" (2009, p. xxi). But how are design activists and other designers endeavouring to use their skills in ethical ways towards ethical ends supposed to identify and understand what the greater good towards which they are so earnestly striving actually is?

Design writers often quote Herbert Simon's definition of design as an activity which "seeks to change existing situations into preferred ones" (1996/1969, p. 111). To conceive of design thus, in terms of change towards preference, would seem to suggest an inherent capability of design as being an ideal tool for responsible and active socially engaged citizenship: design capable of being a stimulus provoking society to move itself from ethically undesirable existing states towards preferred potential ones. However, as Anne-Marie Willis (2013) has noted, it would appear that (with the best of intentions and enthusiasm) designers tend to focus on how to achieve these preferred states without pausing to critically think about what preferred change actually is. This failure to carefully engage with the fundamental nature of the ethical along with the accompanying failure to consider the unique nature of the aesthetic character of design and the implications which this might bring to the ethical context, can undermine and destabilise the foundations of the very idea of ethical design.

As Thomas Markussen has highlighted, if we want to talk meaningfully about the role which design can play in actively effecting changes in society, we must develop a clearer understanding of what exactly it is which is "truly unique and singular" in the act of design in society as opposed to other generic types of activism: "The design act is not a boycott, strike, protest, demonstration, or some other political act; 
instead, it lends its power of resistance by being precisely a designerly way of intervening in people's lives" (2013, p. 38).

At some level, a recurrent concern for society and desire to intervene towards its improvement certainly would appear intrinsic to design's nature. The most cursory of glances into the history of design reveals a regular pattern of what Matthew Soar (2002) has referred to as "periodical widespread crises of conscience" (p. 34) within the field. These recurrent uprisings of social concern have spurred designers to action, inspiring many of what are now seen as canonical moments in conventional design history. Think for example of William Morris' socialist Arts and Crafts concerns, the high-modernist utopian ideals associated with the Bauhaus, etc., and the cultural impact in the work of figures such as Jamie Reid and Vivienne Westwood surrounding the British punk movement. These are just a few among many notable examples illustrating the regularly emerging periodical embodiment of design's concern for society. However these same examples are also notable for their exemplification of the equally regular failure of such attempts to achieve the lasting meaningful societal change so earnestly sought, as apparently revolutionary design interventions are co-opted and assimilated into the status quo. Arts and Crafts becomes a signifier of bourgeois taste rather than an emancipation of the worker from the "useless toil" which Morris (2008/1888) berated. The political ideals of the European modernists become the disposable elements of the new "style" of commercial design in post-war America. Punk becomes nothing more than a "fun" T-shirt to be purchased in high street stores everywhere.

This apparent inability to achieve desired sociopolitical change (failure to save the world) is of course not unique to design. We are surrounded by a world full of complex problems, populated by a society of individuals who mostly feel that they should do something about these, but who for all their good intentions never seem to get very far. In the process of living in the world, we are constantly confronted with what we perceive as real, actual, concrete "problems" in our society. These are issues which might be perceived by different individuals and groups from different angles and with different resulting opinions, but which nevertheless demand (or require responses to others' demands) to be faced. At their very root these response-demanding conundrums which may or may not lead to socio-political actions, are ethical issues.

\section{THE ETHICAL}

The ethical is one of those concepts whose meaning we might naturally assume is generally understood in common by a majority of people. However in any non-superficial discussion of the topic we soon find that our understandings of this term are not as unified as we might have thought. Part of the common assumption is a linkage between the ethical and the moral. This generally manifests in a vague interchangeability between the two terms, which immediately muddies the water.

Etymologically the words ethical and moral are in fact effectively synonymous (the Latin moralis being a direct translation of the Greek ethikos) yet the terms are often used to refer to distinct concepts. There is, however, no universal consensus as to the character of these more specific conceptualizations. In both everyday and specialist language, usage of the two words remains interchangeable, inconsistent and at times wholly contradictory. Without wishing to spend any time on this here other than to simply clarify the positioning used in this instance, the conception of the ethical used in this paper is that which understands the ethical to be neither a body of knowledge nor a value system, but rather a foundational way of being.

Ethical considerations are lived and known unconsciously as an integral part of being human. Moralities on the other hand are socially constructed codes and criteria which stem from the ethical: the ways in which we socially attempt to understand, implement, measure, and evidence the existence of ethics. As such, it is quite possible for moralities to be acted out or adhered to in the absence of ethics. French philosopher Jacques Derrida's (1995) example of rude politeness illustrates this possibility of unethical morality well: "A gesture 'of friendship' or 'of politeness' would be neither friendly nor polite if it were purely and simply to obey a ritual rule. [...] It is impolite to be merely polite, to be polite out of politeness" (p. 7). The "ritual" structures of moralitysocially constructed rules and regulations governing social behaviors - are not in themselves meaningful; they depend on a deeper ethical foundation to underpin their true value.

The shallow (ontic) structure of morals does not necessarily guarantee the existence of a deeper (ontological) ethical being. Conversely, being ethical is not at all synonymous with being good but is rather merely a state in which recognitions and considerations of abstract value differences between certain 
actions or positions are possible. The ethical is therefore agnostic towards good and evil, but is the condition which allows recognition of such values.

\section{DESIGN AND THE ETHICAL}

What is the nature of the relationship between design and the ethical? How might we approach this inquiry? The ethical is an abstract philosophical concept, but it must be recognized that design is no ethereal abstraction. While it may be possible to distill certain abstract characteristics central to an essence of design as we understand it (a welltrodden path for discussion elsewhere), a pragmatic consideration of design in the real-world will find that design exists and is encountered primarily in the activity and output of designers (professional or not). Consideration of the relationship between the ethical and design should therefore start with designers. In the context of this paper, the activities, products and experiences of visual communication (graphic) designers are taken as a starting point, but always with a view as to the parallels with other fields of design.

As I have already alluded to, throughout the history of design, individuals and groups of designers have, in different ways, consistently expressed social, political, ethical concerns and aspirations. This heritage continues into our present experience. Although they may not always be aware of it, ethical discourse occurs regularly among designers. While at times in the recent past it may have been perceived as something of a side-show distraction, in contemporary graphic design discourse, ethical debate is regularly presented as very much part of the mainstream. As an example of this, a brief glance at the "Tools and Resources" page of the AIGA (2013) website reveals a prominent section dedicated to "Ethical standards for designers" as well as resource areas for designers interested in sustainability, designing for social impact, design for democracy, and education. Obviously there are many designers who profess no active professional interest whatsoever in social/ethical issues, but it would be very difficult to accuse the contemporary profession as a whole of not engaging with such topics. The sheer number of people talking about a diverse array of ethical issues tells us at least something about the significant levels of ethical concern, interest and enthusiasm present within design communities today.

In 2013/14 I carried out a series of interviews among a range of practicing visual communication designers in Scotland, discussing at length their own working practices, and their opinions about what constitutes "good" design. In these in depth narratives of unique design experience, a wide and vastly complex range of ethical issues arising in the interviewee's accounts were observed and recorded. Statements emerging in discussions responding to the stimulus of what "good" design might be, range from the cautious: "Now, you know, design isn't a savior really of anything so it's not going to sort out social issues or anything like that, but it can help" ('Lee', freelance designer). To more fundamental expressions tying design's very identity to an expectation of social impact:

That's for me where design lives. Yes form and function, but [...] for me that's the bare minimum it should do. It really should be helping the people it's supposed to help. [...] Not: does it look great? Not: has it won awards? Is it actually improving the lives of the people it's serving. [...] And yeah if it's not doing that then I dunno what it is. ('Robert', creative director of small design studio)

What is particularly interesting in the designers' narratives recorded in the study, is the constant presence of conflict, paradox and ambiguity surrounding this recurring expressed underlying belief in some form of ethical foundation of design.

The same designer ('Robert') quoted above passionately expressing his belief that design must "help" people in order to be considered design at all, later made this statement:

And when I say helping people I also mean just providing stuff that people want to buy, cause that's I suppose nowadays people buy stuff to aspire to a lifestyle ideal that they have in their head I suppose that's helping them as well in that. ('Robert')

For this individual the ethical imperative to "help" people is served by "providing stuff that people want to buy". However another interviewee 'Frank', when asked the question "What do you think the role of design is in society?" gave this more ambivalent response:

In society? There's probably two parts to that, one of which is good and one is bad. The good one is obviously it should in theory make life easier for people. Not just graphic design, product design, everything. [...] The downside to our role in society is that we're obviously ultimately trying to sell shit to people that they don't actually need. ('Frank', principal designer with medium sized design studio)

What one designer ('Frank') sees as the "bad" side of design, another ('Robert') identifies as an ethical responsibility. 
Even when "good" and "bad" are recognized, it is often not a simple choice between the two. 'Frank' recognizes the "bad", yet goes on to describe cases in which he has knowingly violated his personal morals by designing packaging for a children's food product which he knew was "absolutely shocking" in such a way as to appear healthy, and talking of the most enjoyable "wildly creative" work being for cigarette companies even though he detests smoking and its health impacts.

Insights such as these expressed through the interviews illustrate something of the conflicted realities of the practicing visual communication designer's experience of the ethical. How are concerned designers to know what truly ethical design actually is, and find ways of justifying, coping with, and finding resolution in the conflicting and compromised ethical situations encountered in the everyday realities of design practice? What does it really mean to conduct oneself ethically as a designer?

Of course the quandary of ethical action is not specific to design, but is present in the consideration of all our human activity. Sociologist Zygmunt Bauman in his "Postmodern Ethics" (1993) articulates the nature of the contemporary conundrum well:

The once unitary and indivisible 'right way' begins to split into 'economically sensible', 'aesthetically pleasing', 'morally proper'. Actions may be right in one sense, wrong in another. Which action ought to be measured by what criteria? And if a number of criteria apply, which is to be given priority? (p. 5)

Serious attempts to support the ethical potential of design must wrestle with these issues at the levels of both general activity and that which is more specific to the nature of design.

Much has been written of the general level of human behavior. Sociologists like Bauman (1993, p. 19) observe ethical coping-mechanisms such as the "floating" of responsibility through the separation of our-selves from our-actions in role-performing. Philosophers diagnose mental conditions such as Peter Sloterdijk's (2001, p. 5) cynical "enlightened false consciousness" which allows us to continue working despite full and complicit awareness of ethical conflict. The contribution of this paper however, will be to elaborate a concept which has particular relevance specifically to the area of design, namely that referred to in the title as An/Aesth/Ethics.

\section{THE AN/AESTHETICIZATION OF ETHICS}

The concept of an/aestheticization is essentially that by possessing the appearance and sensation of ethicality without the requirement of the authentic existence of ethical being, we can create a cycle in which an aestheticized ethics gives us permission to fail to act ethically. That is to say, we can provide ourselves with the aesthetic sensation of ethical being without the inconvenience of actually having to be ethical. We give ourselves permission to act akrasiastically (akrasia: to act against our better judgment: knowing the right and yet not doing it) by aesthetically simulating either the emotional rewards of upholding ethical standards, or the lack of negative emotional experience associated with ethical shortcomings (Tonkinwise, 2004). Effectively, we anaesthetize ourselves to ethical pain through the process of aestheticizing ethics.

Some of the most obviously concrete examples of this phenomenon surrounding us in the affluent developed world can be identified in those products of "ethical consumerism" such as Toms "One for One" shoes, Fairtrade coffee from Starbucks and brands such as "One" in the UK which uses profits from its bottled water to fund clean water projects in Africa. The premise of such initiatives is that it is possible to do good in the world without having to go out of your way: all gain, no pain. The 0 ne website states: “You don't even need to change your habits, just the products in your shopping basket" (Global Ethics Ltd., 2013).

These products are certainly well meaning, and without doubt do bring about a great deal of good in the world. However, what is the scope of this good and should we be satisfied to operate within these boundaries? While handing out free shoes, should we not also consider why it is that children should be in such desperate poverty so as not to possess their own in the first place? While sipping our Starbucks should we not wonder why global fair trading is the exception not the norm? While quenching our thirst on bottled water which has traveled hundreds of diesel miles from source to mouth, should we not pause to consider our own potential contributions to climate-change related water shortages in Africa? What change would really be "preferable" here? More often than not, instead of spurring us to action on these issues, the products of ethical consumerism instead furnish us with a pre-packaged sense of satisfaction in a job well done.

Such ethical consumerism operates to assuage our guilt and permit our akrasia. We are aware of what "the right" is, yet instead of stepping in that 
direction, we are seduced by a pain-free alternative which looks very much like the right and still provides us with the sensation and displayable symbolic social value of ethical living which we desire, but without demanding that we change our behavior or radically alter any of the underlying systems contributing to the originally perceived ethical dilemmas. As Slovenian cultural theorist Slavoj Žižek writes: "since what really matters is the experience, why not go only for that, bypassing the clumsy detour through reality?" (2009, p. 53).

As we trade in our ethical states of being for an/ aestheticized simulations of these, we fee/ ethical but simultaneously we diminish our capacities for being ethical as we become comfortable with and no longer question our everyday activities. When the ethical impulse becomes a means solely to achieving the sensation of ethical being, an aestheticized short circuit bypassing the necessity for the ethical act to actually take place at all inevitably occurs as the path of least resistance.

\section{AESTHETICS: IMPLICATED}

What has this issue of the an/aestheticization of the ethical got to do with design? The simple answer is that design is inescapably implicated in aestheticization, being necessarily an inherently aesthetic activity.

Evidently-most obviously in the urban West, but increasingly globally-our experiences of life are becoming more and more aesthetically mantled and mediated. Of course, human life, culture and society has always been aesthetic, however increasingly there is a perception of an exponential expansion and acceleration of the aesthetic, reaching further and saturating more completely all areas of human experience.

Design historian and theorist Clive Dilnot (2009) describes this pervasive aestheticization of reality in terms of the expansion of "the artificial" as the context of our lives. Since pre-historic times, humans have existed within and in relation primarily to the context of nature, however with the advent of modernity our capabilities in manipulating and forming the world around us (thus rendering it artificial) have expanded and increased to such an extent that we find ourselves now in the unprecedented historical state in which artifice has finally eclipsed nature as the foundation of our lives and become "the horizon and medium of our existence" (Dilnot, 2009, p. 184). Artifice becomes our medium when we can shape every aspect of our environments and lives, right down to re-designing the structure of our DNA. It becomes our horizon when we become capable of our own complete and final obliteration through man-made nuclear or environmental catastrophe. In this progression design plays no mere supporting role, but that of lead actor. Dilnot defines design in this dynamic as "being precisely that which [...] mediates being in relationship to artifice" (2005, p. 46). We have the power to design not only our present existence, but also our futures, or lack thereof (Fry, 1999).

Design so conceived and observed as the mediator of being within artifice - a central actor involved in creating, shaping and sustaining our perceptions of the world surrounding us - is heavily implicated in the development of the situation of ethical an/aestheticization. At the very least the sheer ubiquity and pervasiveness of design in constituting our sensory and perceptual experience of the social environment denies it the luxury of claiming non-involvement. Design's active and purposeful agency in aesthetically mediating our experience, positively implicates it as playing an active role in the constructing and sustaining of this phenomenon. In constituting our everyday environment-and due to its uncritical failures to interrogate the contextual meanings of "good", "better", "preferred," etc.—design regularly encourages the creation of the mere impression, appearance and sensation of ethicality without engaging the presence of genuine ethical being.

Conveniently illustrating a graphic manifestation of this, Dilnot (2010) has written of this principle at work within Shepard Fairey's "Hope" poster for Barack Obama's 2008 presidential campaign. This image has achieved iconic status and might be claimed by many to be an excellent example of "good" design in that it is supposed to have played a role in inspiring and motivating a public to bring about political change. However it would be a politically catastrophic error to equate the emotional sensation of political change with the actual occurrence of genuine change in the real world. If the mere image of politics can fulfill and satisfy political desires, genuine change is no longer required.

Quoting Roland Barthes' (1972/1957) analysis of the "paternalism", the "anti-intellectualism" and the "spiriting away" of true politics found in the electoral portrait, Dilnot suggests that these are not merely undesirable characteristics for political discourse but are in fact the very antitheses of: "three of the essential axioms - of any adequate democratic politics. Egalitarianism [...] thoughtfulness [...] and the transitive [transformative]" (2010, p. 10). 
Applying Barthes' assessment to the Fairey poster; equality, deliberation and change are displaced from shared responsibilities to qualities to be found in what is no longer Barack Obama the man but the Obama icon. Dilnot writes that:

For politics as whole, this is baleful - the word is an understatement. That truth and agency are defined not as belonging to the collective singularities of all in their role as citizens, but by displacement only to the instruments and agencies of power institutes in even the most 'democratic' societies a fissure that permanently vitiates their operations. Displacement, we should recall, is the most basic of all ideological operations. It is the structural evasion of what is the case. (2010, p. 11, emphasis in the original)

What "is the case" is that, for all he came to be an icon for, the actually existing version of this symbol of hope and change has (not for want of good intentions or effort, but in actuality) achieved little which would have by its own volition engendered the pre-disbursed political sensations inspired by the image alone. To the contrary, a generation of enthusiastic socio-politically concerned individuals who whole-heartedly bought into the image have received a reinforcement at a deeply personal emotional level of what Barthes (1972/1957, p. 91) described as the "elitist essence" of the "paternalistic nature of elections": an affirmation that politics is not in fact concerned with the good of all but with the rise and fall of distant aspirational figures. In summary of the case Dilnot diagnoses: "The problem with the political poster therefore is that even while rhetorically evoking the political, it operates to reduce the capability to act politically" $(2010$, p. 10 , emphasis in the original).

A further example which clearly exemplifies this an/aestheticization of ethical potential, is provided by the case of Invisible Children's "Kony 2012" campaign. The half hour long "Kony 2012" video which calls for action to help speed up the capture of International Criminal Court indicted war criminal Joseph Kony, leader of the LRA militant group active in central Africa, was the fastest ever online video at the time to reach one hundred million views (six days after its publication). Within these first few days, fifty-eight percent of young American adults had become aware of the previously obscure charitable organization Invisible Children and their campaign to "make Kony famous" (Kanczula, 2012). Countless non-profit organizations campaigning for years on similar issues could only dream of such levels of exposure.
The success of Kony 2012 as we now know, was of course short-lived. The passion of millions of young people inspired by a slickly designed video and online campaign to "stop at nothing" on their path to "shaping human history" (Invisible Children, 2012), somehow failed to translate into physical action in the real world. Invisible Children's flagship awareness raising event "Cover the Night" was a complete washout as supporters turned out to be somewhat less passionate in person than they were on Facebook (Carroll, 2012).

While we can speculate upon various reasons as to why the physical participation element of Kony 2012 turned out to be such a damp squib, in this mix it is certainly possible to observe the workings of an/aestheticization. Just as in Dilnot's analysis of the operation of the political poster, in this case it is possible to consider how the powerfully designed rhetorical evocation of ideas of empowerment, participation, and involvement so effectively produced by the Kony 2012 video actually operated to reduce capabilities to act when it came down to it. The aesthetic experience of the sensation of being a part of a triumphant, powerful, emancipatory, world-changing movement had already been pre-dispensed by watching the video, wearing the wrist band and sending a tweet. The design of the campaign, so successful from the moment the video starts to play in immediately inspiring aesthetic sensations of active world changing participatory involvement, also anaesthetizes with the same stroke, cutting short the hunger to actively participate further.

The apparent catch-22 here of course is that the better the aesthetics of the design in captivating, drawing in and involving the individual, the greater the potential for an/aestheticization. It is extremely unlikely that Kony 2012 would have been such a success had their video not been so well designed and produced. Yet perhaps the campaign might have enjoyed longer lasting and more meaningful impact had it offered a less polished, less completely aestheticized experience, instead of negating its own itch with its simultaneous scratch.

This question of an/aestheticization-of the simultaneously anaesthetizing potential of the aesthetic-is one which designers seeking to be truly ethical in their work must address. Failure to do so leaves the keen but naïve designer open to the possibilities of applying their considerable skill and expertise towards projects which display a surface of ethicality but which may in fact effectively serve to suppress ethical potentials as the Obama and Kony examples demonstrate. In the worst of these cases 
good design can become an unconsciously deceptive veneer legitimating ideological positions or behavior patterns which the designer would never have set out to support.

Is design necessarily fated to create and sustain inherently unethical conditions of an/aestheticization? Does design, for all its sporadic Utopian ambition actually pose a constant danger to society? This rather gloomy train of thought brings to mind certain accounts of widespread aestheticization such as those voiced by leader of the Situationist International Guy Debord (1994/1967) in The Society of the Spectacle, and philosopher of postmodernity Jean Baudrillard (1994/1981) in positing the "hyperreal simulacra." Such accounts would give the impression of a largely pessimistic outlook for ethical aesthetics by inferring that because it is the aesthetic which creates and sustains the an/aestheticized condition, aesthetics cannot now behave in any other way than to dig us deeper into this state.

Are aesthetics therefore a lost ethical cause? I do not believe so. In the final section of this paper I will, by introducing the work of German aesthetic philosopher Wolfgang Welsch (1997), attempt to paint a more hopeful picture of the potential relationship between aesthetics and ethics based on Welsch's argument that the ethical is in fact intrinsic to and emergent from within aesthetics, and that therefore the aesthetic is equally capable of returning sensation to those areas which it anaesthetizes.

\section{HOPE FOR DESIGN: THE ETHICAL WITHIN THE AESTHETIC}

In the various essays contained in his collection Undoing Aesthetics (1997), Wolfgang Welsch attempts to uncover and lay bare some aspects of the operation of the aesthetic in society, and in doing so teases out some of the subtle but deep links and connections between the aesthetic and the ethical.

The root of our word aesthetic, comes from the Greek aisthesis referring to the sensuous through a double sense of both perception and sensation. The perceptive element relates to the cognitive recognition of values within aesthetic categories: colors, textures, tastes, smells, sounds. The element of sensation on the other hand relates to the more emotional evaluation of sensory experience on scales of like and dislike, attraction or repulsion. As Welsch draws out, even at this basic level it is possible to begin to identify elements of the ethical actually emerging from within the aesthetic itself. He identifies two fundamentally aesthetic ethical imperatives, for which he puts forwards the neologism aesthet/hic - an obvious contraction of aesthetic and ethical-intended for use to "designate those parts of aesthetics which of themselves contain ethical elements" (1997, p. 61).

The first of these emergences of the ethical from within the aesthetic he refers to as the vital imperative: in which aesthetic sensibility serves the primary ethical goal of the preservation of life. At this level the rudimentary ethical goal of continued survival is facilitated by raw aesthetic perception and sensation. This primordial aisthesis initially serves us to identify distinctions between those objects and situations beneficial or detrimental to our survival. It is practical cognition expressed on a scale of pleasure and displeasure. This can be obviously seen in the instinctive preference of a young child for warmth over cold, and in dislike of bitter foods which might indicate toxicity, etc. This imperative to sustain life is the first foundational ethical imperative, and one which emerges with and through aesthetics. Therefore Welsch classifies it the first aesthet/hic imperative. This vital aesthet/hic imperative is ethics at a primordial level, bearing little resemblance to the complex creature we recognize as ethics today, but it is a starting point nonetheless. As Welsch writes "It served life, keeping yourself alive, and survival (zen, soteria) - but not yet the good life (eu zen)" (1997, p. 63).

The second aesthet/hic imperative which Welsch advances is the elevatory aesthetic imperative: that which requires us to rise above raw sensory aisthesis to a higher level in which aesthetic sensibility serves not only the vital functions of survival but of judgment, reflection, communication and pleasure perceived autonomously from vital concerns and often prioritized and privileged over them. This is elevatory in two senses, firstly that such perceiving must take place in a state of reflection raised above the immediate pleasure/pain concerns of survival, but secondly, because it is this ability to rise above purely physical vital concerns in which, Welsch suggests, is found the "anthropological difference" (1997, p. 64): that which sets us apart from and above those other living creatures and inanimate objects who lack this capacity for higher level reflection. He draws attention right back to Aristotle who suggested that what makes humans superior animals is their ability to recognize and act upon not just the raw vital sensuous values of useful and harmful, but also higher aesthetic qualities whose recognition requires abilities of reflection and communication: better and worse, just and unjust, beautiful and ugly, harmonic 
and discordant etc. Welsch emphasizes the absolute importance of this seemingly innocuous observation, writing:

Insofar as we are living creatures, the vital imperative is our first aesthet/hic imperative too and the elevatory imperative just the second. But, insofar as we are humans, the elevatory imperative is our constitutive and decisive imperative. In human terms it is the categorical imperative par excellence. (1997, p. 64)

The human-ness of humanity is found in positive response to the demand to rise above matters of base survival. One who fails on this account to rise above mere physical existence by possessing aesthet/hic sensitivity, though walking and humanoid in form, cannot be said to be human in the full sense of the word.

Such a being would be reminiscent of the horrifying figure of the "Muselmann", a name given to the living dead of the Nazi concentration camps: the empty shell of a human being who has been de-humanized in every way. In Remnants of Auschwitz, Giorgio Agamben (1999) documents eyewitness accounts of these Musselmänner, quoting from among others the testimony of internee Jean Améry:

“The so-called Muselmann, as the camp language termed the prisoner who was giving up and was given up by his comrades, no longer had room in his consciousness for the contrasts good or bad, noble or base, intellectual or unintellectual. He was a staggering corpse, a bundle of physical functions in its last convulsions." (p.41)

The human who has relinquished his ability to aesthetically "rise above" is really no human at all. It is in this sense that Welsch posits aesthetic sensitivity as the ultimate human categorical imperative: if there is something which humans must do-because to not do this means to lose precisely what it means to be human -it is to maintain our grasp on the capability to rise above the physical. It is through this elevatory aesthet/hic imperative to seek to rise above the raw physical sensuous that we can begin to recognize connections and linkages between the aesthetic realm and phenomena more easily recognized as ethical in nature.

In illustration of this linkage between aesthetic sensation and perception and the ethical, Welsch gives the example of tolerance. A man who has perfectly internalized the principles of tolerance would still be able to practice the most extreme injustices, and with the clearest of consciences, were he to lack the aesthetic sensibility to recognize the differences between himself and his fellow man which are to be tolerated. The moral code of tolerance-the an/aestheticized surface-may be subscribed to, but the truly ethical act of being tolerant of difference slips by unnoticed as the difference itself is not attended to. As Welsch writes: "Sensibility for differences is thus a real condition for tolerance. - Perhaps we live in a society which talks too much of tolerance but possesses too little sensibility" (1997, p. 27). The examples of the Muselmann and Welsch's intolerant man serve to demonstrate how the absolute lack of aesthetic sensitivity precludes the existence of ethics. Conversely therefore we can see that aesthetic sensitivity is a fundamentally prerequisite foundation to the ethical.

What impact does this insight have on the question of design's role in an/aestheticization? Building on this aesthetic foundation for ethics, Welsch argues that aesthetics actually contains within itself the capabilities to combat an/aestheticization. If the aesthetic, which has been implicated in the anaesthetizing of ethics is, at its very root, fundamentally ethical, then surely it also contains within itself potentials to equally promote sensation, perception and reflection on issues of ethics leading to a more, rather than less ethically sensitive society.

\section{AESTHETIC JUSTICE}

Welsch calls for the development of a "genuinely aestheticized culture" (1997, p. 25) built not on empty an/aestheticized structural morality but on radically aesthet/hic ethical being. Such an objective is perhaps more easily said than done, particularly considering the historical antagonism between the disciplines of aesthetics and ethics. Since antiquity (from Plato's stance towards the poets, to various periods of religious/secular iconoclasm) the aesthetic has been considered by many to be a dangerous threat to society, something to be controlled and regulated in the name of ethics. In modernity the aesthetic to some extent escaped this oppression but by the same stroke rendered itself impotent by becoming entirely separated and irreconcilable from ethics through the appeal to autonomy. Subsequently, as Welsch writes "aesthetic viewpoints have had no role to play for modern ethics since Kant" (1997, p. 60).

Welsch links these traditional separations of aesthetics and ethics to a critical misunderstanding of the aesthet/hic imperatives. Traditional approaches generally, once the elevatory aesthetic imperative has been established, part company with and look down upon the raw, base, animalistic sensory aisthesis of 
the vital imperative. In following the imperative to rise above raw sensibility traditional aesthetic thinking makes the critical error of rejecting raw aisthesis wholesale. Such strategies result in the "perversion" of true aesthetics in pursuit of programs of aesthetic "domination, banishment and regimentation" (1997, p. 68). These are the projects by which aesthetic judgment becomes the reserve of the privileged elite and must be preserved and protected from contamination by those lower impulses of the common masses.

It does not take much effort to bring to mind examples of this type of thinking within the design world. The massive and enduring snobbery surrounding the use of certain typefaces in graphic design is but one example. Designers, who pride themselves on being a creative and diverse group can equally be some of the worst culprits in forcefully imposing their own visions of aesthetic perfection.

In pursuing the authentic ethical potential of aesthetics, Welsch rejects these traditional aesthetic absolutisms drawing instead upon the aesthetic thinking of Theodor Adorno in his assertion that the power of the aesthetic is not to be controlled and regulated but is an emancipatory force in its own right.

Regulation which would seek to impose universal aesthetic standards leads inevitably to the trap of the intolerant man. In Adorno's Negative Dialectics, (2004/1966) he speaks out against the uncritical assumption that equality and justice naturally go hand in hand, positing a distinction between two types of implied justice: legalistic justice and aesthetic justice. "In law the formal principle of equivalence becomes the norm; everyone is treated alike. An equality in which differences perish secretly serves to promote inequality" (p. 309).

Formal equality of all before the eyes of the law would appear to be a rationally desirable condition. What Adorno points out is that where such equality is manufactured among people through the crushing of genuinely existing differences, this cannot properly be called just. A principle of radical equality such as that theoretically demanded by modern legal systems runs the risk of becoming a principle of homogenization. Under such a system justice can be done to the homogenized average figure but never to the unique, different and heterogeneous. While it is of course absolutely necessary to seek common grounds and patterns in society, in reality there is no universal homogeneity, only absolute heterogeneity. It is only through openness to the aesthetic perception and recognition of differences that "justice to the heterogeneous" (Welsch, 1997, p. 68) can properly emerge.

\section{DESIGNING A BLIND-SPOT CULTURE}

In a state of total aestheticization, our overwhelmed senses lose track of that which has been excluded. As Welsch writes:

Total aestheticization results in its opposite. Where everything becomes beautiful, nothing is beautiful any more: continued excitement leads to indifference; aestheticization breaks into anaestheticization. It is, then, precisely aesthetic reasons which speak in favor of breaking through the turmoil of aestheticization. Amidst the hyperaestheticization aesthetically fallow areas are necessary. (1997, p. 25)

Aesthetic strategies - those which lie at the heart of design activity-are perfectly placed to carve out these fallow areas in ethically an/aestheticized realities. Aesthetic interventions can create the necessary spaces for reflection in which attention and awareness in relation to the exclusions and blind spots we have created for ourselves can be recovered.

Proper aesthetic sensitivity, is by its nature attentive towards that which is different and excluded. While legalistic justice is interested in blanket principles which can apply to a range of situations, aesthetic justice embraces the plurality of the singular in which each unique situation or individual is dealt with according to their uniqueness and difference. Welsch writes:

In that reflected aesthetic consciousness is sensitized for fundamental differences as a matter of principle it is able to recognize and to respect the peculiarity and irreducibility of forms of life more easily than widespread social consciousness, which denies alterities rather than acknowledging them. Hence an aesthetically sensitized awareness can also become effective within the life-world by illuminating, clarifying and helping out. The readiness is constitutively built in to be critically attentive of borders and exclusions, to see through imperialisms and-being, as a matter of principle allergic to injustice - to intervene wherever excessive domination is found and wherever the rights of the oppressed must be espoused. (1997, p. 26)

The aesthetic's predisposition towards justice to the heterogeneous allows us to see how it is in fact specifically aesthetic sensitivity which best allows us to conceive of the ethical. The challenge for truly 
ethical design then is to find ways of unlocking this aesthet/hic potential: to be a practice not of an/aestheticization but rather a practice of the implementation of aesthetic interventions which draw attention explicitly to our ethical blind-spots, constantly disrupting and destabilizing existing an/aestheticized equilibriums.

A shift in the gear of aesthetic production from hyper embellishment, enhancement, and experience, to a more reflective mode which draws attention to that which we do not notice would be able to foreground precisely the objects of our inattentions, nurturing an atmosphere of much greater sensitivity to differences, exclusions, oppressions and intolerances. This possibility, which Welsch calls a "blind-spot culture" (1997, p. 25), offers the hope that design is not fated to an/aestheticize but does in fact hold within itself the potential to be properly ethical if only the terms of its aesthet/hic nature would be renegotiated.

How can such a blind-spot culture be encouraged? What could practical ethical aesthetic strategies to subvert an/aestheticization and encourage genuinely ethical aestheticization be for design, which for so long has been a principal contributor to an/aestheticization? These questions pose difficult yet not insurmountable challenges in the pursuit of an ethical design practice.

The majority of graphic design activity falls far short of this goal of genuine ethics. The most well-intentioned strategies of design activism can be subsumed within the expectations of the status quo producing an/aesthetic mainstream. Cases such as the International Advertising Association's woeful 2009 "Hopenhagen" campaign-effectively a corporate greenwashing exercise at the Cop-15 climate change conference-demonstrate the potential abuses of design in the name of ethical causes (Boehnert, 2011). Even radical groups such as Adbusters who attempt to appropriate conventional design strategies as a means of protest and resistance become hopelessly predictable and ignorable (Adbusters, 2014).

It is however possible to discover traces of what we might call blind-spot practices at work within the realms of contemporary visual communication design. Recent years have seen the rise of an emergent wave of so called "critical" and "speculative" design practices (Kyes \& Owens, 2007; Ericson, Frostner, Kyes, Teleman, \& Williamsson, 2009; Sueda, 2014). In the best instances amongst the work of designers linked to these developments we can discern shadows of possible blind-spot practices as we find designers questioning the possibilities for what graphic design can be and how it can operate within society.

Designers such as the Dutch groups Metahaven and Experimental Jetset (each in their own very different ways) demonstrate tantalizing possibilities for radical reconceptualizations of design and the use of aesthetic form to break with conventional operations of visual communication, thereby creating new spaces for critical thinking. To a great extent, however, many of these speculative critical interventions appear as yet to be in an embryonic state, their actually-existing experimental aesthetic forms often failing in practice to live up to their theoretical promise.

We should, though, of course not make the mistake of believing that such emergent blind-spot practices are entirely new phenomena. Following the Dutch critical design trajectory back to the nineteen seventies, the work of Jan van Toorn provides us with an example of a design practice which successfully combined and implemented a deep theoretical knowledge of and concern for the ethical power of the image into practical aesthetic strategies through his trademark techniques of dialogical and journalistic image production (van Toorn, 2006; Kuijpers, 2013).

Employing the aesthetic means of design to return vision to our ethical blind-spots has always been and always will remain a possibility. The aesthetic capabilities of design are always active in constituting and re-constituting our everyday realities. The challenge of creating a blind-spot culture for each new generation is to find the specific techniques which will be most effective for drawing attention to the overlooked, repressed and neglected within the present nature of this constantly changing aesthetic environment. The good news is that these capabilities are always already potentially present within the aesthet/hic nature of design. As Clive Dilnot has written:

design is the discovery of what the artificial can be for us. Since the artificial is also today the frame of our possibilities as human beings, to discover what the artificial can be for us is to discover what our possibility can be and hence (here its third dimension) it is also a discovery of what possibility can be. (Dilnot, 2009, p. 84)

We must find hope in the possibility that design, precisely due its aesthetic nature, has the in-built potential to be used to return feeling to a society which finds itself constantly numbed to ethical being. 


\section{REFERENCES}

Adbusters. (2014). Journal of the mental environment. Retrieved from: https://www.adbusters.org/

Adorno, T. W. (2004). Negative dialectics. (Taylor and Francis e-library, 2004 ed.). London: Routledge. Originally published, 1966.

Agamben, G. (1999). Remnants of Auschwitz: The Witness and the Archive. New York: Zone Books.

AIGA. (2013). Tools \& Resources. Retrieved August 15, 2013, from http://www.aiga.org/Resources/

Barthes, R. (1972). Mythologies. London: J. Cape. Originally published, 1957.

Baudrillard, J., \& Glaser, S. F. (1994). Simulacra and simulation. Ann Arbor, Mich.: University of Michigan Press. Originally published, 1981.

Boehnert, J. (2011, September). Hopenhagen: Design activism as an oxymoron. Paper presented at Design activism and social change: The design history society annual conference, Barcelona. Retrieved from http://www.historiadeldisseny. org/congres

Carroll, R. (2012, April 21). Kony 2012 Cover the Night fails to move from the internet to the streets. The Guardian. Retrieved from http://www.theguardian.com/world/2012/apr/21/ kony-2012-campaign-uganda-warlord

Debord, G. (1994). The society of the spectacle. New York: Zone Books. Originally published, 1967.

Derrida, J., \& Dutoit, T. (1995). On the name. Stanford, Calif.: Stanford University Press.

Dilnot, C. (2009). Ethics in Design: 10 Questions. In Clark, H. \& Brody, D. (Eds.), Design Studies: A Reader. (pp.180-190). Oxford: Berg.

Dilnot, C. (2010). Being Prescient Concerning Obama, or Notes on the politics of configuration (part one). The Poster. 1(1), 7-29. doi: 10.1386/post.1.1.7_1

Ericson, M. Frostner, M. Kyes, Z. Teleman, S. \& Williamsson, J. (2009) laspis Forum on Design and Critical Practice: The Reader. Berlin: Sternberg.

Fry, T. (1999). A new design philosophy: an introduction to defuturing. Sydney: University of New South Wales.

Fuad-Luke, A. (2009). Design activism: Beautiful strangeness for a sustainable world. London: Earthscan.

Global Ethics Ltd. (2013). Do One Good Thing. Retrieved June 26, 2013, from http://www.onedifference.org/do-one-good-thing

Invisible Children. (2012, March 12). Kony 2012. [Video File]. Retrieved from http://invisiblechildren.com/kony-2012/

Kanczula, A. (2012, April 20). Kony 2012 in numbers. The Guardian. Retrieved from http://www.theguardian.com/news/ datablog/2012/apr/20/kony-2012-facts-numbers

Kuijpers, E. (2013). And/Or: On Contradiction in the Work of Jan van Toorn: Extended. Rotterdam: nai010 publishers.

Kyes, Z. \& Owens, M. (Eds.). (2007) Forms of Inquiry: The Architecture of Critical Graphic Design. London: AA Publications

Laranjo. (2014, April 16). Critical Graphic Design: Critical of What? Retrieved from http://designobserver.com/feature/ critical-graphic-design-critical-of-what/38416
Markussen, T. (2013). The Disruptive Aesthetics of Design Activism: Enacting Design Between Art and Politics. Design Issues, 29(1), 38-50. doi:10.1162/DESI_a_00195

Morris, W. (2008). Useful work v. useless toil. London: Penguin. Original publication, 1888.

Simon, H. A. (1996). The sciences of the artificial(3rd ed.). Cambridge, Mass.: MIT Press. Original publication, 1969.

Soar, M. (2002). Graphic Design / Graphic Dissent: Towards a Cultural Economy of an Insular Profession. (Doctoral dissertation). Retrieved from http://www.mattsoar.org/dissertation/ GraphicDesignGraphicDissent.pdf

Sueda, J. (2014). All Possible Futures. London: Bedford Press.

Tonkinwise, C. (2013). Ethics by design, or the ethos of things. Design Philosophy Papers, (2), Retrieved from http://academia.edu/1204142/ Ethics by Design or the Ethos of Things

van Toorn, J. (2006). Design's Delight. Rotterdam: nai010 publishers.

Welsch, W. (1997). Undoing aesthetics. London: SAGE.

Willis, A. (2013). Design change and politics. Design Philosophy Papers, (1), Retrieved from http://www.desphilosophy.com/ $\mathrm{dpp} / \mathrm{dpp}$ journal/journal.html

Žižek, S. (2009). First as Tragedy, Then as Farce. London: Verso.

\section{CORRESPONDENCE}

Peter Buwert, School of Arts \& Creative Industries, Edinburgh Napier University, Merchiston Campus, 10 Colinton Road, Edinburgh, Scotland, UK, EH10 5DT E-mail: p.buwert@napier.ac.uk

Published online 12 November, 2015 ISSN 1749-3463 print/ISSN 1749-3471 http://dx.doi.org/10.14434/artifact.v3i3.3960 (C) 2015 Artifact 